\title{
Interphase Engineering with Nanofillers in Fiber-Reinforced Polymer Composites
}

\author{
József Karger-Kocsis ${ }^{1,2}$, Sándor Kéki ${ }^{3}$, Haroon Mahmood ${ }^{4}$ and \\ Alessandro Pegoretti ${ }^{4 *}$ \\ ${ }^{1}$ Budapest University of Technology and Economics, Faculty of Mechanical \\ Engineering, Department of Polymer Engineering, Budapest, Hungary \\ ${ }^{2}$ MTA-BME Research Group for Composite Science and Technology, Budapest, \\ Hungary \\ ${ }^{3}$ University of Debrecen, Department of Applied Chemistry, Debrecen, Hungary \\ ${ }^{4}$ University of Trento, Department of Industrial Engineering, Trento, Italy
}

\begin{abstract}
This chapter surveys recent advancements in the interphase engineering of fiberreinforced polymer composites using different nanofillers. The nanofillers are classified based on their aspect ratio. The strategies followed are discussed separately for stress transfer improvement or adding functionality in the interphase. For improved stress transfer from the matrix to the fiber the nanofillers are deposited on the surface of the reinforcements by different techniques resulting in physical or chemical adhesion. Bulk matrix modification enhances the interphase properties, as well. Special attention is paid to report on efforts focused on the creation of (multi)functional interphase in polymer composites by using nanofillers. Added functionalities provide sensing, self-healing and damping properties. This chapter also includes state-of-the-art knowledge on the characterization and modelling of the interphase. In the outlook section some challenges and perspectives in the engineering of fiber/matrix interphase are summarized.
\end{abstract}

Keywords: Nanocomposite, interphase, nanofillers, carbon nanotubes, graphene, graphene oxide, interfacial shear strength, interlaminar shear stress, multiscale modelling.

${ }^{*}$ Corresponding author: alessandro.pegoretti@unitn.it

Anil N. Netravali and K.L. Mittal (eds.) Interface/Interphase in Polymer Nanocomposites, (71-102) (C) 2017 Scrivener Publishing LLC 


\subsection{Introduction}

Composites are defined as materials consisting of two or more distinct phases with a recognizable interphase between them. This definition is usually restricted in practice to materials containing fibrous reinforcements or reinforcements with different length to cross-section dimensions (referred to aspect ratio), which are embedded in a matrix. Composites can be classified based on their matrix nature (metal-, ceramic - or polymer-based, thermoplastic and thermosetting polymers), origin (natural, synthetic), appearance (e.g. discontinuous or continuous fibers) and alignment (e.g. random, unidirectional, cross-ply) of the fiber reinforcement, fiber architecture (e.g. non-woven, woven, knitted, braided), etc.

Fibers are inherently stronger than the bulk materials because the probability of imperfections (inherent flaws) decreases with decreasing dimension. The stiffness and strength of the most important reinforcing fibers, such as glass (GF), carbon (CF), aramid (AF), natural fiber (NF) are markedly higher than those of polymeric matrices. The matrix transfers the load to the fibers and distributes the stress among them. The matrix is also responsible for protecting the fibrous reinforcement from the environment and allows the necessary positioning of the fibers. The fiber/matrix interphase guarantees stress transfer from the "weak" matrix to the "strong" fiber and from fiber to fiber through the matrix, as well. The term interphase, meaning a finite interlayer with distinct physico-chemical properties between the fiber and matrix, was introduced in the 1970s [1]. The load transfer capability of the interphase depends on the fiber/matrix adhesion which can be physico-chemical, or frictional, or both, in nature [2]. Physico-chemical contribution, including chemical reactions, intermolecular interactions, surface-induced crystallization, phase separation phenomenon, etc. seem to be the more important in polymer-based composites than the frictional contribution. Nevertheless, "roughening" of the fiber surface and amplifying the difference in thermal contraction between the fiber and matrix turned out to favour stress transfer [3]. In many cases both chemical and frictional components are operative though not explicitly mentioned or addressed.

Because the interphase is a key factor in composite performance, its design has been the focus of interest in both academia and industry. Properties of the interphase should be tailored by considering various parameters, such as the locally prevailing stress field, possible environmental attack, service temperature, service life expectation, etc. Moreover, considering the fact that the dominant failure mode in fiber-reinforced polymers is interphase-related (debonding between fiber and matrix), its detection and even its healing are highly desired. 
Next we shall report on effects of nanofillers in the interphase of polymeric composites. Incorporation of nanofillers into the interphase was spurred mainly for the following reasons:

1. to improve the stress transfer between the matrix and fibrous reinforcements, and

2. to provide the interphase with functional properties.

Enhancing the stress transfer capability is the traditional role of the interphase. Nanofillers can contribute by "roughening" the fiber surface, reduction of the stress transfer length (i.e. reduction of the critical aspect ratio of the fiber), and stress redistribution via stress field homogenization (through diminishing stress concentration effects). Surface roughening is beneficial not only for improving the frictional component of adhesion, but also for toughening. The crack developed at the interface or in the interphase is forced to follow a zig-zag route owing to the nanofiller particles which act as local obstacles. It is obvious that higher energy dissipation is involved in a zig-zag crack path (involving various nanofiller - and matrix-related failure events) than in a planar one. One would think that the above-mentioned beneficial effects can be triggered only from the fiber side via coating and deposition of the nanofillers. This, however, is not the only option. In fact, matrix modification with nanofillers may influence the interphase characteristics, as well, as demonstrated later.

The other and very recent aspect of interphase engineering is related to the functionality. This development is fuelled by the efforts to produce (multi)functional materials. Albeit different definitions exist for (multi) functionality, the most straightforward classification considers whether or not the related properties are of colligative nature, i.e. linked with each other or not. (Multi)functional materials often have structural (mechanical) and non-structural (sensing, actuation, barrier, self-healing, controlled release, etc.) properties. It was recognized that some functionalities could be achieved through straightforward modification of the interphase instead of the bulk. If failure starts in the interphase, as mentioned above, then its detection, and eventual healing, should also be considered if possible. Sharma et al. [4] provided a review on the research works on carbon-fiber based composites which also considers interphase modification strategies using nanofillers. A comprehensive survey on this field, also addressing the effects of nanofillers in the interphase, was recently published by KargerKocsis et al. [5].

In the following part of the chapter the recent developments are introduced by grouping them according to whether the related strategy was 
mainly developed for the stress transfer function or for the functional performance of the interphase.

\subsection{Interphase Tailoring for Stress Transfer}

\subsubsection{Coating with Nanofillers}

All reinforcing fibers used for the preparation of polymer composites are surface treated and/or coated, usually during their manufacturing steps. This kind of coating is usually referred to as sizing. GFs are usually sized immediately after spinning to protect them from fracturing. The aqueous formulation of GF sizing contains an adhesion promoter, a film former along with a suitable emulsifier and a lubricant. Sizing is commonly applied also for CFs. During their production, CFs may be subjected, however, to various surface treatments in order to remove the weak outer layer and introduce oxygen containing functional groups [6,7]. Other polymerbased reinforcing fibers, such as aramid fiber (AF), ultra-high molecular weight polyethylene (UHMWPE), polybenzoxazole-types (PBO), thermotropic liquid crystalline polymers (LCPs) are sized, as well. By contrast, natural fibers (NFs), are usually not sized but subjected to different surface treatments. The latter may be classified as physical or chemical treatments as proposed by Fuqua et al. [8].

It is intuitive that the most straightforward method for the surface modification of fibers is to incorporate the nanoparticles directly into the sizing formulation. In fact, this is one of the preferred practices. The incorporated nanofillers are mostly of high aspect ratio with platy (disk) or fibrous (needle) shapes. As platy reinforcements, clay (layered silicate) and graphene derivatives, while as fibrous ones, carbon nanotube (CNT) variants (single, double and multi-walled - SW-, DW - and MWCNT, respectively) are preferred in the sizing formulations. For the surface "coating" of NFs the deposition of bacterial cellulose nanoparticles, produced by fermentation, was also attempted [9]. It is noteworthy that the nanofillers are mostly physically adsorbed in the interphase though weak chemical bonding, such as H-bonding, is not excluded.

The nanofillers can be deposited onto the fiber surfaces, or other reinforcing structures, by dip coating, spraying and electrostatic/electrophoretic techniques. These processes are schematically depicted in Figure 2.1.

Reinforcing fibers were sized with formulations containing CNTs, clay, graphene oxide (GO) which all have rather high aspect ratios. As mentioned before, the related dispersions are applied to the fiber surface by 


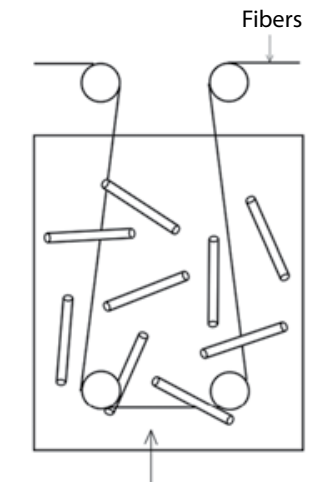

(a) CNT dispersion

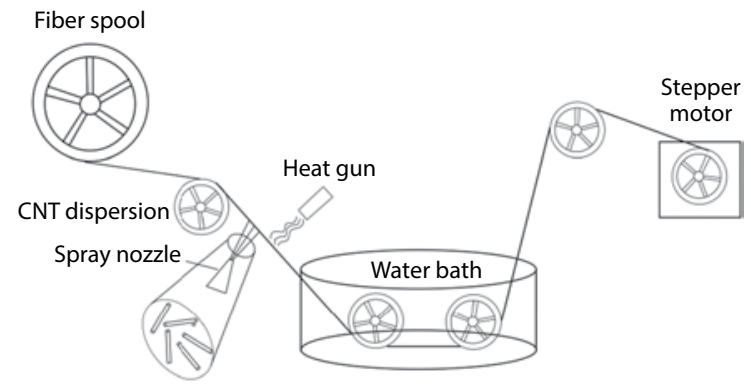

(b)

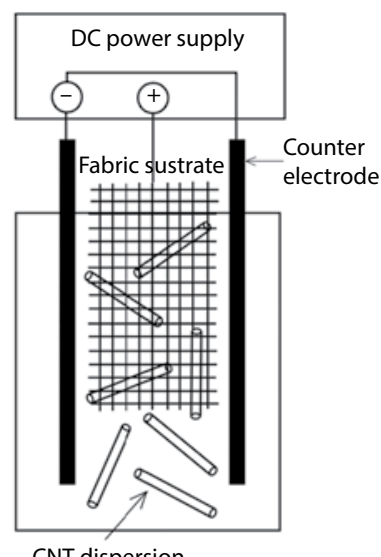

Figure 2.1 Schematics of typical surface coating techniques of fibers and related fabrics: (a) dipping, (b) spraying, and (c) electrophoresis.

dipping or spraying techniques. The improvement in the stress transfer is generally evaluated on single fiber microcomposites and real macrocomposites (unidirectional fiber and woven fabric layer reinforced laminates). In case of single fiber microcomposites, the interfacial shear strength (IFSS) is determined using single fiber fragmentation and microbond tests. The macrocomposites' performance is characterized by interlaminar properties, viz. interlaminar shear strength (ILSS) deduced from short beam shear (SBS) test and interlaminar fracture energy values determined under mode I (crack tip opening, $\mathrm{G}_{\mathrm{IC}}$ ) and mode II ( planar shear, $\mathrm{G}_{\mathrm{IIC}}$ ) conditions. The above test configurations are depicted schematically in Figure 2.2. A detailed description of the interface-relevant test methods 


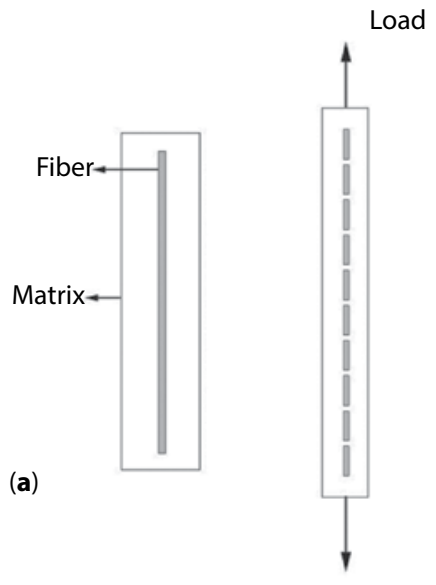

(c)

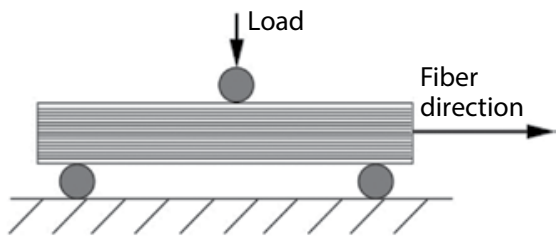

i)
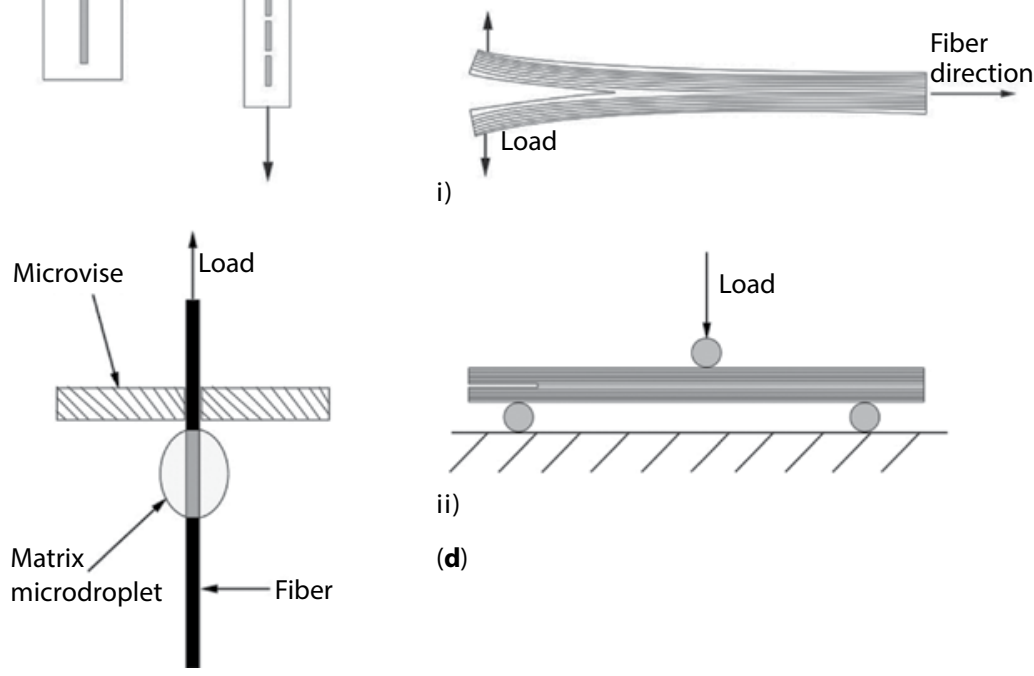

ii)

(d)

(b)

Figure 2.2 Schemes of test configurations to determine interfacial and interlaminar properties: (a) single fiber fragmentation (IFSS), (b) microbond (IFSS), (c) short beam shear (ILSS), (d) interlaminar fracture under (i) mode I and (ii) mode II loadings, respectively $\left(\mathrm{G}_{\mathrm{Ic}}\right.$ and $\left.\mathrm{G}_{\mathrm{IIc}}\right)$.

is out of the scope of this review and the interested reader is addressed to references $[10,11]$.

Effects of single - and multiwalled CNTs, with and without functional groups (mostly carboxyl) in the sizing compositions, applied by dipping and spraying on GF - and CF-reinforcements, have been investigated in various micro - and macrocomposites. For GF-reinforced composites polypropylene (PP) [12], epoxy resin (EP) [13-15], vinyl ester resin (VE) [16] were used; whereas for CF-reinforced ones EP [17] and VE [18] were selected as matrices. The cited works reported remarkable improvements in the IFSS and ILSS (up to 50\%) values. Carboxyl-functionalized CNTcontaining coating was also applied on NFs, such as jute [19] and flax [20]. 


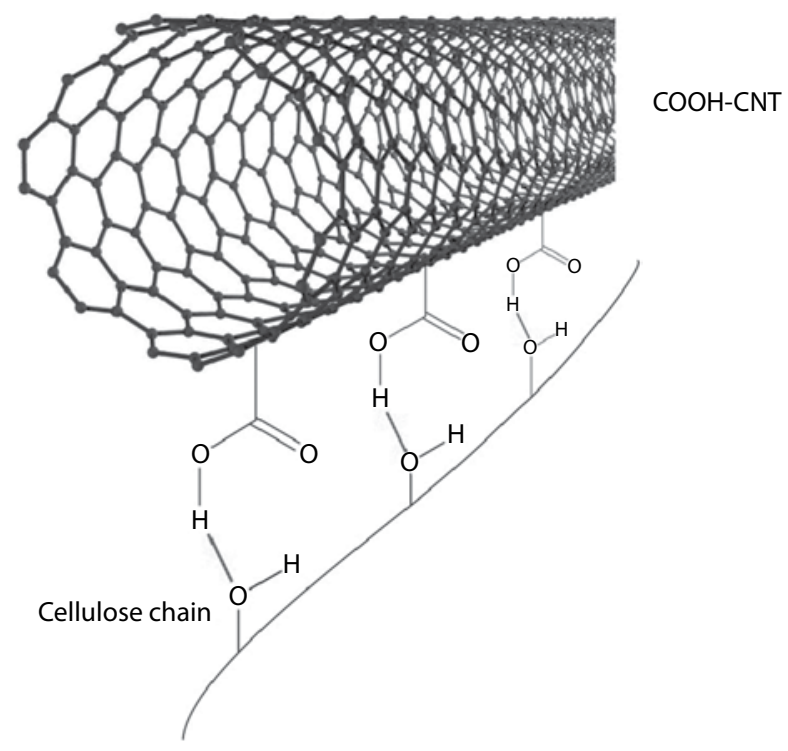

Figure 2.3 H-bonding between the surface hydroxyl groups of NF and carboxyl groups of CNT (adapted from [20]).

The good adhesion between the NF surface (hydroxyl groups) and CNT (carboxyl groups) was attributed to H-bonding, schematically depicted in Figure 2.3.

The interlaminar properties of CNT-coated woven flax reinforced EP-composites were investigated as a function of the CNT content, as well. The ILSS and $\mathrm{G}_{\mathrm{IC}}$ at $1 \mathrm{wt} \%$ CNT coating were higher by $20 \%$ and $31 \%$ respectively, than the control [20]. An interesting approach was demonstrated by Lee et al. [21] who sprayed a dimethylformamide solution containing polyacrylonitrile (PAN) and functionalized MWCNTs onto CF woven fabric followed by a thermal "stabilization" process for PAN at $300{ }^{\circ} \mathrm{C}$. Reinforcement with this CNT-grafted CF fabric yielded $22 \%$ improvement in the tensile strength of the composite.

Attempts were also made to coat the reinforcement by 2D nanofillers, mostly using clay and graphene nanoplatelets. Clay was deposited on $\mathrm{CF}$ and tested in polyetherimide matrix [22]. The effect of graphene oxide (GO), deposited on CF, has been tested in EP-based composites [23-25]. GO was dispersed in the sizing solution with the aid of sonication. GO in the interphase improved the ILSS by almost 20\% [24] and $30 \%$ [25].

Researchers have also pursued the "surface roughening" concept using $0 \mathrm{D}$ (i.e. spherical type) nanofillers. Basalt fiber (BF) yarn and unidirectional (UD) fabrics were post-coated with fumed silica with and without 
additional silanization and embedded in VE. The ILSS was found to be $20 \%$ higher by this treatment compared to the control composite [26].

Using various dipping and spaying techniques for the surface "nanostructuring" of the reinforcements generally did not yield a uniform and homogeneous distribution of the related nanofillers on the substrate surfaces. Though some improvements were noticeable when sonicating the nanofiller-containing sizing dispersion, a homogeneous surface covering remained a challenge. To overcome this problem, electrostatic (ESD) and electrophoretic deposition (EPD) methods were recommended. In these deposition processes, charged particles are deposited on a substrate (generally a fiber) which has an opposite electrical charge. Accordingly, attractive forces between positively charged nanoparticles and negatively charged reinforcing materials, or vice versa, were exploited to obtain a homogeneous deposition of nanofillers. CF can be easily made anionic via suitable oxidation. On the other hand, nanofillers, such as CNT, can be rendered cationic using cationic polymers such as polyelectrolytes. The concept of ESD is depicted schematically in Figure 2.4.

ESD differs from EPD due to the fact that in the latter the required electrical charging of the reinforcement is achieved by coupling to an electrode (cathode, anode) the potential of which depends on the charge of the corresponding nanofillers (cf. Figure $2.1 \mathrm{c}$ ). As a consequence, the ionic movement in EPD is "forced" in contrast to ESD. The group of Drzal [27] has shown that cationic polymer treated MWCNT can be uniformly deposited in ESD on CF having a negative charge owing to its surface oxidation in a

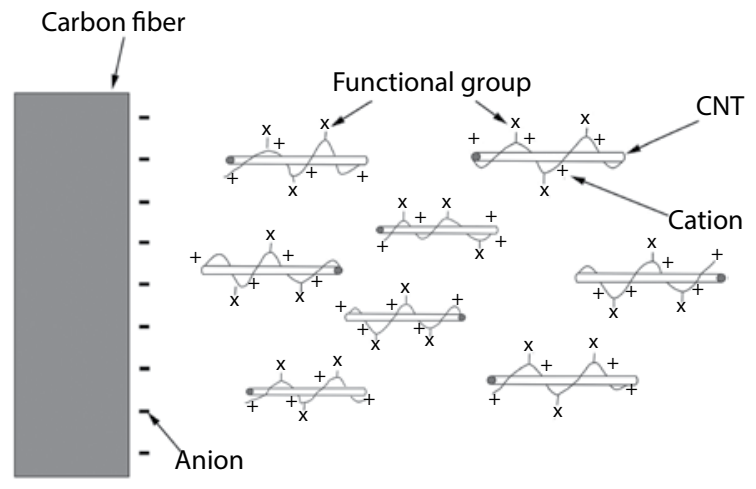

Figure 2.4 Schematic visualization of how attractive forces between positively charged nanoparticles and negatively charged reinforcing materials can be exploited to obtain a homogeneous deposition of nanofillers. In this case, carbon fibers can be negatively charged via suitable oxidation and carbon nanotubes can be rendered cationic using polyelectrolytes. (adapted from. [27]). 
suitable sizing electrolyte. When a cationic polymer such as polyethyleneimine (PEI) was selected, which was co-reactive with both the sizing and matrix (EP), then very high IFSS values were reached. This was shown in single fiber fragmentation tests (cf. Figure 2a). Rutz and Berg [28] used ESD to coat GF with $0 D$ silica nanoparticles. GF was functionalized also with an epoxysilane, while the silica nanoparticles by PEI. The $\mathrm{pH}$ range of the coating dispersion in which the silica particles had positive and the GF negative charge was properly selected for the ESD procedure. The authors studied also the effects of the silica particles size. It was reported that too small particles $(16 \mathrm{~nm})$ were not efficient though adhered well to the GF surface due to small roughening effect. Large particles (71 and $100 \mathrm{~nm}$ ) were poorly adhered, and thus did not improve the stress transfer even if the surface roughening effect was sufficiently high. The best performance was found for $26 \mathrm{~nm}$ size silica particles which adhered well to the GF and also improved the surface roughness at the same time. The IFSS, measured in single fiber fragmentation test, was $35 \%$ higher than that of bare GF, but only $8 \%$ higher than that of silane treated GF.

Unlike ESD, EPD has received more attention for nanofiller deposition on the reinforcement surfaces. Similarly to ESD, the electrical charge of the nanofillers is achieved by functionalization. For this purpose MWCNTs are generally oxidized to impart carboxyl groups. In their aqueous EPD dispersions non-ionic surfactants can be used. This approach was followed for both GFs [5, 15] and CFs fabrics [4, 5, 17, 29]. Another option is to use cationic CNT modifications, such as amine functionalization. Note that amine functionality can also be established by reacting suitable functional groups of oxidized CF with PEI. Trials were also made in this direction with different reinforcements [30,31], and the outcome was checked usually in EP-based composites. Nowadays, great efforts are devoted to sonication-assisted EPD techniques to create nanofiller coated, "hierarchically structured" reinforcements [32]. Sonication is aimed at overcoming the settling of nanofillers in the aqueous coating dispersions. It is, however, accompanied by other phenomena (prominent change in ion movement, diminishing of bubbling owing to water electrolysis) which are poorly understood at present.

This is the right place to give some clarification on the terminology. Different descriptions have been introduced for the interphase modification by nanofillers in composite materials containing traditional fibers and related fabrics. One can find the terms "multiscale", "hierarchical", and "hybrid" often in the open literature. "Hybrid" seems to be improper as it is already reserved to indicate the presence of two or more different reinforcements. Composites with multiscale reinforcements are typically 
those which contain nano - and microscale reinforcements (which may be of different types and thus are also hybrids) simultaneously [33]. The term hierarchical may also be misleading since it is generally used to indicate the structural hierarchy of composite structures [34], namely: macro (real component), meso (plies, tows, yarns), and micro levels (fibers). Nonetheless, we shall keep the terms "hierarchically structured fiber or interphase" due to their wide acceptance. The hierarchical structure can be interpreted as a combination of microscaled fiber and nanoscaled filler which are in "intimate" contact (physical or chemical adsorption) with each other. Apart from the sizing/coating approaches summarized above, such "intimate" contact can be achieved also in other ways which is the topic of the next section.

\subsubsection{Creation of Hierarchical Fibers}

As shown in Section 2.1., sizing/coating of the reinforcement by nanofillers represents a promising route for interphase engineering. Recall that the nanofillers in the related coating are "physically fixed" on the surface. The next logical step is to "anchor" the nanofillers on the fiber surface. This may be achieved by chemical reactions. A further option is to let the nanofiller "grow" directly on the fiber surface. Both of these processes are often termed as "grafting".

\subsubsection{Chemical Grafting of Nanofillers}

For chemical coupling of carbonaceous nanofillers they have to be functionalized. Though various functionalization methods have been investigated, the most efficient ones are oxidative treatments via wet chemistry. The resulting functional groups $(-\mathrm{COOH},-\mathrm{OH}$, epoxy) serve as coupling sites for further reactions. For the desired coupling, however, the surface of the reinforcing fibers should also have accessible reactive groups for the target chemical reactions.

Grafting of carbonaceous 1D (i.e. CNT, CNF) and 2D (i.e. graphene and graphene-like [35]) nanofillers may be a possible approach for GF, having inherent functionality $(-\mathrm{OH})$. Note that GF has hydroxyl groups on the surface which can be converted easily into amine groups. The amine groups may react with the carboxyl ones of graphene oxide thus yielding an amide coupling between GF and GO. This chemical route, applicable for CNT as well, is summarized in Figure 2.5.

By using the SBS tests, Chen et al. [36] have shown that the ILSS of EP composite reinforced with GO grafted GF was $20 \%$ higher than those 

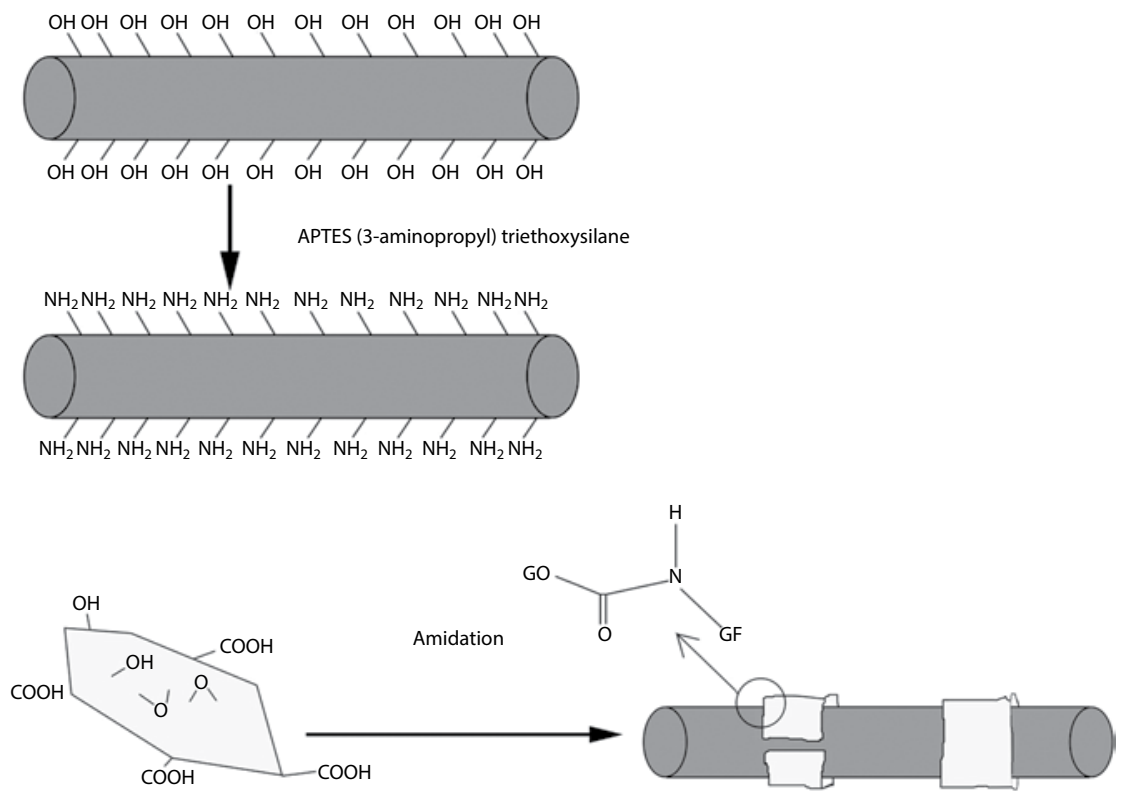

Figure 2.5 Schematic representation of how oxidized carbonaceous nanofillers (in this case GO) can be grafted onto GF surface (based on. [36]).

reinforced with GO coated GF (physical sorption), and almost 50\% higher than that containing unmodified GF.

\subsubsection{Chemical Vapor Deposition (CVD)}

Creation of "hairy" fibers by directly growing CNTs or carbon nanofibers (CNFs) onto the fiber surface has many benefits. The advantages include the enhancement of the fiber surface area, possibility of mechanical interlocking, capillary sorption of the liquid matrix, and local reinforcement of the interphase. All of the aforementioned aspects contribute to a better stress transfer from the matrix to the fibers. The major goal with composites containing hierarchical fibers is the improvement of the out-of-plane (transverse) properties without sacrificing the in-plane ones. It is obvious that radically grown CNTs or carbon nanofibers (CNFs) with suitable length and at a sufficiently high surface coverage (concentration) may work for transverse reinforcement. As a consequence, their effects appear both in enhanced inter - and intralaminar properties.

CVD growth of nanotubes, nanofibers, and nanowires can be considered as a renewal of the whiskerization process from the mid-1970s [37]. 
Instead of generating silicon carbide or nitride single crystals at high temperatures $\left(1300^{\circ}-1800{ }^{\circ} \mathrm{C}\right)$, CVD results in nanoscale fibrous structures at much lower temperatures $\left(600-800^{\circ} \mathrm{C}\right)$. CVD is typically based on the following two steps: i) coating of the fiber or fiber assembly with a proper catalyst, and ii) growth of the nanofibers in a reactor using hydrocarbon sources. These two steps may be merged, as, for example, in the so-called injection CVD where deposition of a catalyst containing solution and pyrolysis of the hydrocarbon source take place simultaneously. The first report on CVD deposition of carbon nanofibers on CF dates back to 1991 [38]. The deposited structure was herring bone/platelet-like carbon. CNTs were first synthesized by Thostenson et al. [39] on CF by thermal CVD using predeposited metal catalysts on the CF surface. CNT-based hierarchical reinforcement in composites was already the subject of a review [40] in which the authors focused on the improvements in composite performances. When $1 \mathrm{D}$ carbon nanofillers are produced on $\mathrm{CF}$ surface then one can say all-carbon hierarchical fibers. However, when a non-carbon fibrillar structure is created on CF, or a carbonaceous one on a non-CF substrate then the term hybrid hierarchical fiber seems to be more appropriate.

Although GF is not well suited for grafting with CNTs due to its low temperature stability, Wood et al. [41] reported a successful case. The authors let MWCNTs grow on GF precoated with a Ni/Fe particle catalyst. GFs were plasma treated and drawn through a CVD chamber with carbon source gas and nitrogen at $\mathrm{T}>600{ }^{\circ} \mathrm{C}$. MWCNTs preferentially grew radially up to $7 \mu \mathrm{m}$ length and densely covered some portions of GF, while they were absent from other parts. EP-composites with such hybrid hierarchical fiber reinforcement exhibited a 35\% higher stiffness of the interphase compared to the bulk. The growth of carbon nanomaterials on GF was also recently reported by Rahaman and Kar [42] who described an electroless plating method for achieving a uniform coating with nickel catalyst. Carbon nanostructures were grown over GF using thermal CVD technique. In particular, vertically aligned CNFs were obtained at $500{ }^{\circ} \mathrm{C}$, while MWCNTs were obtained on the GF at 600 or $700{ }^{\circ} \mathrm{C}$. Note that the "chemical coupling" onto the GF surface is in this case promoted by the catalyst particles.

As already emphasized, the plurality of the works have addressed the production of hierarchical all-carbon reinforcements in CVD batch processes. The related studies utilized various catalysts, carbon source gases, CVD conditions but the reinforcing action of the resulting fiber/fabric was studied usually in EP-resins [39, 43-46]. The improvement in the interfacial/interlaminar properties of the composites with hierarchical $\mathrm{CF} /$ CNT(CNF) structures showed scatter in a wide range, from 15\% [39] to $175 \%$ [45]. A further general result of these studies was that the tensile 
strength of the parent CF was reduced owing to the CVD treatment. The reduction varied between $10 \%$ to $33 \%[39,45,47]$. This negative effect was attributed to penetration of the catalysts in the CF and to damages in CFs induced by the high temperature of the CVD. To avoid this negative effect, CF surface was covered with a protective layer prior to catalyst formation [46]. De Greef et al. [48] demonstrated in a systematic study that the temperature of the CVD was the key factor which negatively affected the tensile strength of CF. Low CNT growth temperatures (at about $500{ }^{\circ} \mathrm{C}$ ) did not cause degradation in the tensile strength of the CFs.

Kim et al. [49] improved the adhesion of the CVD-produced CNT forest on $\mathrm{CF}$ in an innovative way. The authors used radiofrequency sputtering and atomic layer deposition to generate first a $\mathrm{Ti}$ and then an $\mathrm{Al}_{2} \mathrm{O}_{3}$ layer followed by formation of a Fe film by electron beam evaporation on top. The last served as catalyst for the thermal CVD. In another series $\mathrm{SiO}_{2}$ was produced instead of Ti by low pressure CVD. This layer was "anchored" onto $\mathrm{CF}$ by formation of $\mathrm{SiC}$ interlayer. This resulted in a $\mathrm{G}_{\mathrm{IC}}$ improvement by up to $80 \%$ in epoxy/carbon composites. Another straightforward method was to generate a protective layer that could also play the role of catalysts in a subsequent treatment [50].

Another option is to use high temperature resistant fibers/fabrics, such as alumina [51], quartz [52, 53], $\mathrm{SiC}$ [54] and silica [55] for CNT growth through CVD. The corresponding hybrid hierarchical reinforcements yielded prominent enhancements in the IFSS (>150 \% [55]) and interlaminar $\mathrm{G}_{\mathrm{IC}}(>300 \%$ [54]).

Though CVD is a very promising approach for interphase engineering, there are several challenges with the catalytic CVD processes. The growth temperature of the CNTs is quite high and thus it should be reduced in order to minimize fiber damage. Some of the catalysts and carbon sources are toxic and thus should be replaced, as well. The interaction of the CF with the catalysts (dissolution, eutectic formation) under the CNT growth conditions should be better understood and tailored accordingly.

\subsubsection{Other "Grafting" Techniques}

An increase in the surface area and an effective mechanical interlocking can be triggered by the grafting of non-carbon nanofibers or nanowires onto the reinforcing fibers. This approach has been followed by the group of Ehlert [56,57]. These authors have created $\mathrm{ZnO}$ nanowire arrays on the surface of various reinforcing fibers, such as $\mathrm{AF}$ and $\mathrm{CF}$. The idea behind this was the finding that $\mathrm{ZnO}$ interacts strongly with carboxylic functional groups. Carboxylic groups can be produced on the surface of many 
reinforcing fibers by suitable techniques. In case of AF the amide bond is first cleaved by $\mathrm{NaOH}$, and then the $\mathrm{Na}^{+}$is exchanged by $\mathrm{H}^{+}$to create $\mathrm{COOH}$ functional groups. This group participates with $\mathrm{Zn}^{2+}$ ion in a coordination complex acting as seeding and anchoring site for the growth of $\mathrm{ZnO}$ crystal (cf. Figure 2.6). The maximum temperature during the whole grafting process, comprising several steps, is $150^{\circ} \mathrm{C}$ (and that of the $\mathrm{ZnO}$ growth is even less, namely $90^{\circ} \mathrm{C}$ ), which is far below the temperature reached in CVD methods. The IFSS in an EP, determined in single fiber fragmentation test, was enhanced by $51 \%$ when $\mathrm{ZnO}$ "nanowired" $\mathrm{AF}$ was tested instead of bare AF. A further advantage of this approach is that the AF tensile strength was not affected negatively by the nanowires deposition

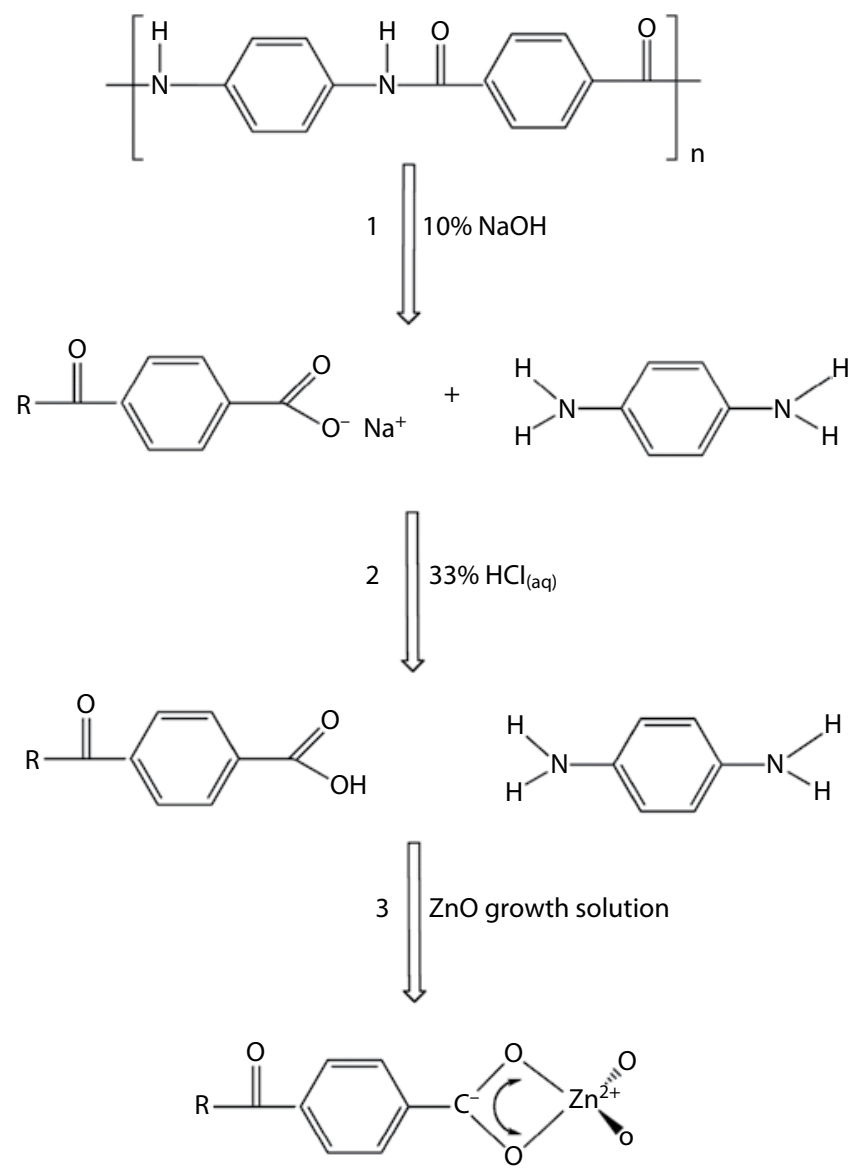

Figure 2.6 Reaction pathway of triggering $\mathrm{ZnO}$ growth on $\mathrm{AF}$ surface through cleavage of the amide bond [56]. 
process. Recall that a reduction in the fiber tensile strength is an undesired general "side effect" of CVD treatments.

This $\mathrm{ZnO}$ "nanowire whiskerization" approach was also adapted for CF subjected to various surface treatments to produce functional groups, the presence of which was attested by XPS analysis [57]. The IFSS of EP-microcomposites correlated with the concentration of the surface ketone groups of $\mathrm{CF}$, which participated in the coordination complex with $\mathrm{Zn}^{2+}$. $\mathrm{CuO}$ nanowires were also "grafted" on CF fabric by Deka et al. [58]. The corresponding composites exhibited higher modulus, strength and impact energy absorption, viz. $33 \%, 43 \%$ and $137 \%$, respectively, compared to the baseline composite with untreated CF fabric.

This kind of seeded nanowire formation from solution on reinforcements may be a very promising route for interphase engineering. The major benefits are: no or less reduction of the fiber tensile properties, growth at relatively low temperature, and possibility of achieving multifunctionality. In fact, $\mathrm{ZnO}$ display piezoelectric and semiconductor properties, which may be exploited in advanced composites for sensing applications [59]. $\mathrm{MnO}_{2}$ nanosheets may have similar functions, though recommended in the cited work for other purpose [60]. This is also the case for the deposition of other nanoparticles, such as silver [61].

\subsubsection{Effects of Matrix Modification with Nanofillers}

It was early recognized that the matrix composition and its microstructure might influence the fiber/matrix interphase and thus the performance of the corresponding composites [62].

Zhang and coworkers [63] studied the effect of rigid spherical silica nanoparticles (up to $20 \mathrm{wt} \%$ ) on the CF/EP adhesion as assessed by the transverse fiber bundle test. Finite element analysis was performed to determine the distribution and the effects of the thermal residual stresses. On the basis of the results obtained, the authors concluded that nano-silica particles in the EP did not noticeably affect the interfacial bonding. By contrast, improvements in the IFSS and ILSS values of CF/EP composites were reported by Hossain et al. [64] when the matrix was modified with the addition of $1 \mathrm{D}(\mathrm{CNT})$ and 2D (clay, graphene) nanofillers. In fact, the ILSS of a CF woven fabric reinforced EP was increased by about $15 \%$ through incorporation of $0.3 \mathrm{wt} \%$ of amine-functionalized CNTs. This was attributed to possible reaction of the amine groups of CNT both with the epoxy group of the bulk EP and epoxy group of the silane sizing of the CF fabric. Ma et al. [65] developed a technique to enrich the interphase of $\mathrm{CF} / \mathrm{EP}$ composites with CNF during vacuum bagging using a porous membrane 
and reported about an almost twofold increase in ILSS. Gojny et al. [66] used carbon black and amine-functionalized DWCNT to modify the EP matrix used to prepare GF-fabric reinforced composites via resin transfer molding (RTM). Incorporation of $0.3 \mathrm{wt} \%$ carbon black and DWCNT-NH improved the ILSS of the composites by $8 \%$ and $15 \%$, respectively.

The $\mathrm{G}_{\mathrm{IC}}$ of an unsatured polyester resin (UP) reinforced with GF fabric was enhanced when CNFs were incorporated even in less than $1 \mathrm{wt} \%$ in the matrix. At higher CNF loading and without surfactant coating of CNF, the nanofillers were filtered off by the GF fabric during the resin infusion process [67]. It is worthwhile to underline that the effect of nanofillers in some of the cited works is not fully interphase related. The positive effect observed is due to multiple crack deviations caused by the nanofiller in the interlaminar layer. The group of Pegoretti has shown that clay [68] and graphite nanoplatelets (GNPs) [69] incorporation in bulk EP may improve the IFSS of GF. An IFSS enhancement of about 30\% was attributed to a better GF/EP wettability [68], better mechanical properties of the EP matrix, and positive influence of GNP on the chemical affinity between GF and EP [69].

Positive effects of bulk matrix modifications with $0 \mathrm{D}$ (spherical), $1 \mathrm{D}$ and 2D nanofillers were also observed with thermoplastic resins. Pedrazzoli and Pegoretti [70] found that the IFSS, measured by the single-fiber fragmentation test on PP/GF microcomposites, could be markedly enhanced by incorporating fumed silica up to $7 \mathrm{wt} \%$. The best result was achieved when the matrix contained $5 \mathrm{wt} \%$ dimethyldichlorosilane functionalized silica and $5 \mathrm{wt} \%$ maleated polypropylene (PP-g-MA) coupling agent. For this nanocomposite, an IFSS value of about $25 \mathrm{MPa}$ was found which was much higher than that with the PP matrix ( 3 MPa). The observed effect was attributed mostly to changes in the surface energetics. According to a recent work of the same group [71], IFSS between GF and PP was enhanced by addition of GNP to the PP. The initial IFSS of about $3 \mathrm{MPa}$ was increased up to about $14 \mathrm{MPa}$ in presence of $7 \mathrm{wt} \%$ GNP. A matrix with the ternary composition PP/PP-g-MA/GNP $=90 / 5 / 5 \mathrm{wt} \%$ yielded an IFSS value of almost $28 \mathrm{MPa}$. The work of adhesion between fiber and matrix correlated well with the IFSS data. Arao et al. [72] demonstrated that the IFSS between PP and CF could be considerably enhanced by PP-g-MA (from 8.6 to $18.9 \mathrm{MPa}$ ) and even further with various types of nanofillers (silica and alumina nanoparticles, CNT, clay). According to single fiber pull-out tests, the IFSS data on the nanocomposites of composition $\mathrm{PP} / \mathrm{PP}-\mathrm{g}-\mathrm{MA} /$ nanofillers $=95 / 4 / 1 \mathrm{wt} \%$ showed the order silica $>$ alumina $>\mathrm{CNT}>$ clay. An improvement in the fiber/matrix adhesion has been found also with organoclay containing thermoplastic matrix 
composites and especially with polyamides [73-75]. Vlasveld et al. [73] argued that the observed effect was related to the matrix stiffening induced by the organoclay because higher matrix modulus would give higher IFSS due to the improved stress transfer via the interphase. By contrast, Isitman et al. [75] ascribed this effect to the development of higher compressive residual stresses in presence of nanofillers at the fiber/matrix interface.

The effect of bulk modification on the fiber/matrix bonding is not trivial. Enrichment of the the interphase with nanofillers is most likely when they bear functional groups and may interact with those on the fiber surface. On the other hand, the wettability of the matrix is affected via changes in the surface tension and viscosity properties. Thermal contraction may be at work, too. Therefore, further works are needed to clarify how the matrix modification influences the interphase properties.

\subsection{Interphase Tailoring for Functionality}

Current research and development activities are focusing on the creation of a functional interphase. A (multi)functional interphase may accomplish tasks besides its traditional structural role (stress transfer). Among the additional functionalities, sensing, actuation, healing, and damping are the most studied ones.

(Multi)functional interphases can be created by different ways which had been partly already introduced in Section 2.2. Next we summarize some of the approaches which have addressed sensing/damage detection, self-healing/repair and other functional properties of the interphase in polymeric composites.

\subsubsection{Sensing/Damage Detection}

The possibility to achieve a sensing response with carbon nanotubes (CNTs) was originally proposed by Fiedler et al. [76]. It was early recognized that the in situ sensing of stress, strain and damage would be a powerful tool for structural health monitoring. This fact directed researchers to concentrate on sensing options in the interphase. In this regard, one of the straightforward strategies is to make use of the well-established sizing/ coating techniques.

Formation of an electrically conductive network of CNT, CNF or graphene in the polymer matrix surrounding the reinforcing fibers allows in situ sensing of deformation and damage. As Chou et al. [77] concluded, a nano-scale conductor is needed to sense the onset of micro-sized crack. 
This concept has been recently pushed forward by transferring the conductive network from the matrix to the interphase.

The group of Mäder explored the damage sensing possibilities of MWCNT networks deposited on the surface of various non-conductive reinforcing fibers, such as GF [13, 15, 30] and NF (jute) [19] by sizing/coating (cf. Section 2). The authors demonstrated that the GF with MWCNTcontaining coating had similar piezoresistivity (i.e. change in the electrical resistance on mechanical loading) as CF. This finding allows us to detect the local strain, and also to sense the onset and growth of damage. The electrical properties of MWCNT coated GF in the form of single fibers in UD-composites changed as a function of stress/strain, temperature and humidity. This feature can be used to detect piezoresistive effects (damage onset, cf. Figure 2.7) and even the glass transition $\left(\mathrm{T}_{\mathrm{g}}\right)$ in the interphase.

The above results may open new routes for in-situ structural health monitoring of polymer composites. Luo et al. [78] described the fabrication of $1 \mathrm{D}$ fiber sensors. These sensors are composed of GF, AF and poly(ethylene terephthalate) (PET) fiber substrates which were spray coated with SWCNT. During composite fabrication the sensor may deliver information about the curing and cooling induced shrinkage through

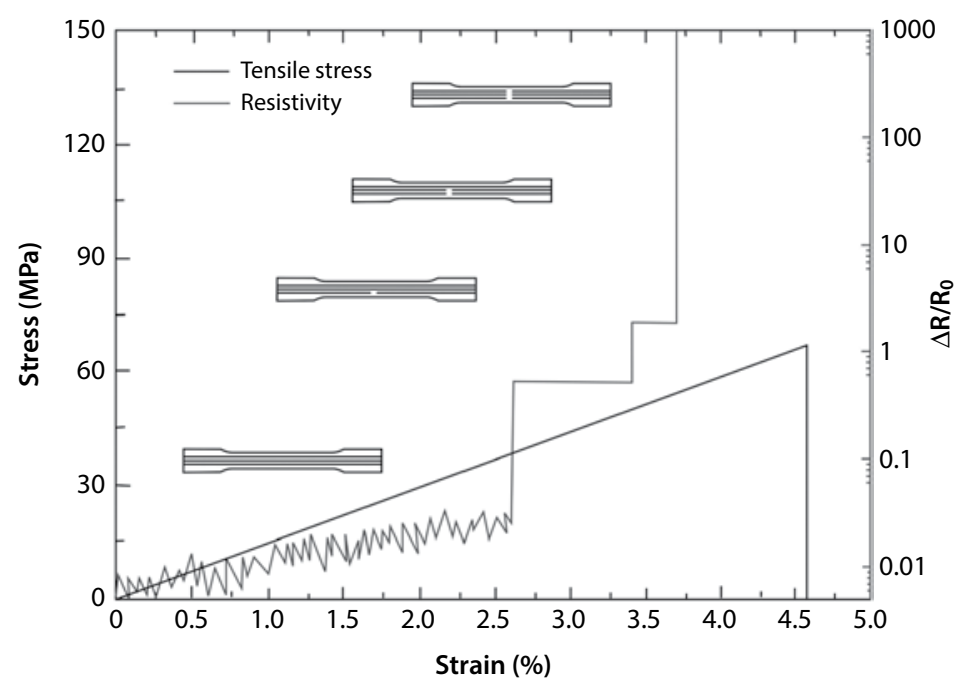

Figure 2.7 Simultaneous changes in stress and resistivity $\left(\nexists R / R_{0}\right)$ as a function of tensile strain for a GF/EP microcomposite with three single GFs. Note: GF was sized with a MWCNT containing formulation (adapted from. [30]). The conductivity, determined by the percolated MWCNTs in the interphase, changes when the percolation network is locally disrupted owing to fracture/debonding events of the reinforcing fibers schematically represented inside the dog-bone samples. 
strain detection. The sensor (called "FibSen") built in the composite may be used for mapping the stress/strain state under various loading modes. The major benefit of the "FibSen" $1 \mathrm{D}$ fibers is that their diameter is smaller or comparable with those of the reinforcing fibers of the composite unlike the currently preferred optical fibers which are much thicker.

Zhang et al. [79] demonstrated the damage sensing capability of spray coated CNTs on CF prepregs in the corresponding UD-fiber composites. By this technique not only the $\mathrm{G}_{\mathrm{Ic}}$ was improved by $20 \%$, but also the reliability of the damage sensing. Note that between the UD aligned conductive CFs the electrical resistance changes by tunneling. By contrast, disruption of the conductive CNT percolation network is responsible for the resistivity change in the interphase of the CNT-modified composites. An interesting alternative is to produce a reinforcing fiber having piezoelectric coating. In a theoretical work, Lin and Sodano [80] predicted that this was feasible and the related piezoelectric structural fiber could be used for sensing/actuation and structural health monitoring.

\subsubsection{Self-Healing/Repair}

"Biological composites" in nature respond to damage through complex autonomic healing mechanisms. Their adapting and mimicking capabilities are the driving forces for research also in the composites field. This approach is also fuelled by the need for damage detection in composite structures. If the damage onset cannot be detected reliably then triggering autonomous (automatic) self-healing in the composites may be the right strategy. Development in this field started again with the bulk modification of polymers prior to focusing on the interphase. As underlined before, the interphase is usually the weakest region in composites where damage starts. Therefore, the interphase should be made capable of self-healing/ repair functions. The principle of the capsule-based self-healing in the interphase is depicted in Figure 2.8.

In capsule-based self-healing systems the healing agent is stored in microcapsules. Their rupture, caused by damage (typically by crack growth) releases the content of capsules that produces "healing". The efficiency of this healing strategy has been confirmed for bulk materials, especially for EP. There are different encapsulation techniques and strategies [81]. Not all of the methods developed for bulk materials are suitable, however, for the interphase. Jones and coworkers $[82,83]$ adopted the solvent-based healing chemistry for a single-capsule approach. They encapsulated the healing epoxy along with a solvent in a urea/formaldehyde resin-based (UF) shell. The latter was produced in situ by reacting urea with formaldehyde 


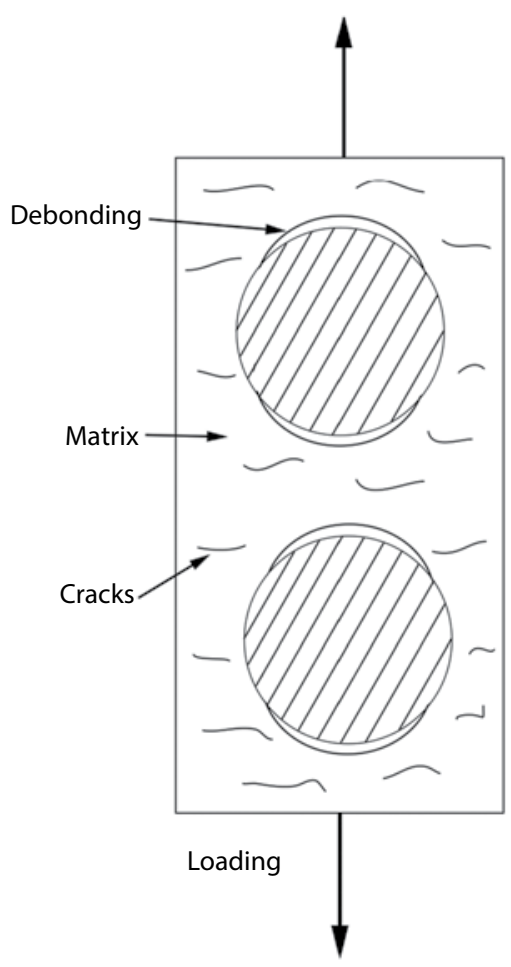

(a)

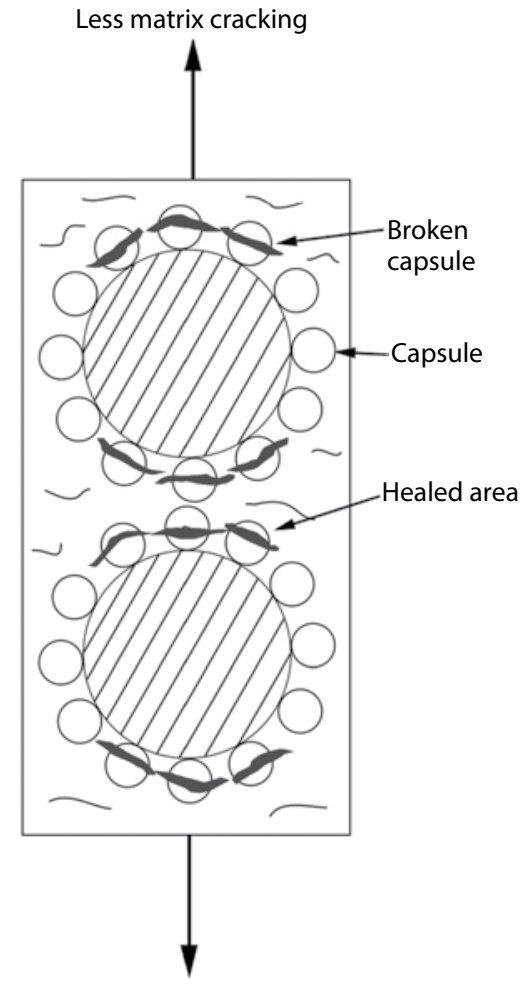

(b)

Figure 2.8 Scheme of the self-healing process in the interphase triggered by the capsuletechnique: (a) un-healed case, (b) healing promoted by the agent contained in the microcapsules surrounding the fibers. When stress is applied, the stress concentration around the fibers causes breakage of capsules and the consequent release of the healing agent contained in the same. The result is less matrix cracking in the healed damaged system.

in oil-in-water type emulsion. The big challenge was to produce nanometer sized capsules and place them on the surface of the reinforcing fiber. The healing process involved swelling of the EP matrix by the solvent, thereby allowing the healing epoxy to reach the residual reactive amine groups of the EP resin. The GF fibers were dip coated in an aqueous suspension containing the capsules [82], whereas for CF a binder formulation was necessary to stabilize the capsules on the CF surface [83]. The healing efficiency, measured in repeated microbond tests, reached up to $80 \%$. The beauty of this solvent based epoxy healing is that the stoichiometry is not relevant. This, however, should be taken into account when the healing resin and hardener are separately encapsulated. 


\subsubsection{Damping}

The vibration damping of composite materials is often too low for some applications. Vibration suppression can be attained by increasing the loss modulus to which the interphase may markedly contribute [84]. Recall that in advanced composites containing UD fibers in $70 \mathrm{vol}$. \% there is practically no bulk matrix anymore. Since the vibration energy can be dissipated via frictional interactions, slippage between the fiber and matrix could be beneficial. This can, however, be triggered by using hierarchical fibers produced by whatever means as reinforcements. CNT-CNT interactions and CNT-matrix frictional stick-slip effects may be efficient energy dissipation mechanisms. This strategy was followed by Tehrani et al. [85] who used catalytic chemical vapour deposition (CVD) utilizing a relatively low temperature synthesis technique named graphitic structures by design (GSD). The CNT coated CF fabric reinforced EP showed considerably higher loss modulus in the frequency range $(1-60 \mathrm{~Hz})$ studied than all other reference composites (raw, heat treated, sputter coated, and CVD coated). Accordingly, hierarchically structured reinforcing fibers may also improve the damping of the corresponding composites [54].

\subsection{Outlook and Future Trends}

The recent developments in interphase engineering should help in the characterization, testing and modelling of the interphase in composites.

For chemical analysis of the fiber surfaces, several techniques have been well established. Jesson and Watts recently reviewed the main experimental techniques for the interface and interphase characterization [86]. To assess the surface functionality and heterogeneity, atomic force microscopy, and its variants have been shown to be useful [87]. Testing of microcomposites is often coupled with other techniques, such as laser Raman microscopy. This has been adapted also for the fragmentation test of microcomposites with hierarchical fibers [88]. Apart from microbond and pull-out tests, nanoindentation is frequently used to determine the interphase thickness and assess the changes therein via mapping [89-91]. Results obtained with nanoindentation of composites with hierarchical fibers suggested that this technique might be problematic owing to the onset of locally arising stresses [92].

To gain a better understanding of the role of MWCNT grafted CF on shear deformation in microbond and fragmentation tests, a molecular dynamics model was developed [93]. The simulation predicted that MWCNT grafting enhanced the shear modulus and strength of the interphase compared to the matrix. Romanov et al. [94] demonstrated in a 3D finite element model 
that CNTs grown on CF alter the stress distribution in composites, in fact. In this model a 3D unit cell of UD CF composite (volume fraction of CF $=0.6$ ), with and without CNT forest on the CF surface was subjected to transverse tensile loading. The stress field was analyzed using the embedded regions technique. Figure 9 presents the contour plots of the maximum principal stress in the matrix for the composite with and without CNTs. In the former case the density of the CNT forest was varied (low, high).

It is obvious from Figure 2.9 that CNT grafting drastically changed the stress distribution in the interphase. Through CNT "foresting" the stress concentration at the fiber/matrix interface can be markedly suppressed. Modelling the interphase region due to nanoparticles incorporation is a hot topic nowadays $[95,96]$.

Interphase engineering is benefitting from the ongoing extensive research on nano-fillers and nano-composites. Some of the recent developments with polymer nanocomposites, marking a change from structural toward functional properties, will be very likely adopted to tailor the interphase properties. Attempts will be made to combine sensing with actuation function. Self-diagnostic options for structural health monitoring will also be addressed. Moreover, novel functions may be explored, such as separation of the heat conduction from the electric one, thermal regulation by

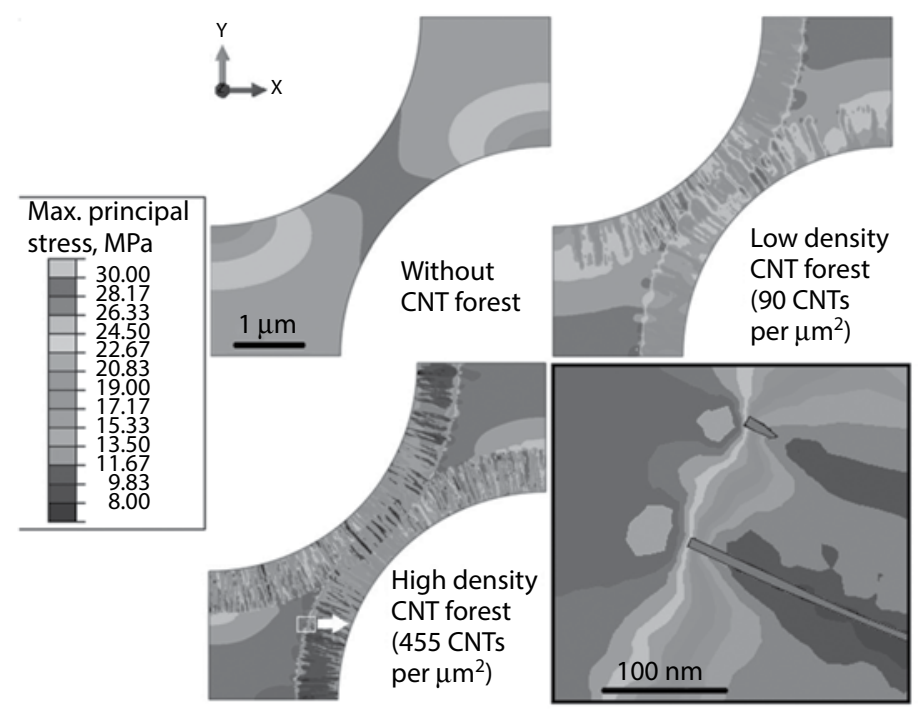

Figure 2.9 2D contour plots of the maximum principal stress in a composite with UD aligned CFs without and with CNT forests on their surfaces. Notes: loading occurred in the $\mathrm{x}$-direction. The density of the grown CNT on the hierarchical CF has also been considered. (adapted from Ref. [94]). 
phase-changing material coatings, electromagnetic interference shielding. Creation of novel functional properties in the interphase should not compromise, however, its traditional load transfer role.

Interphase engineering will be supported by extensive modeling with more and more refined multiscale approaches. The input parameters of these models will be deduced from complex tests. For example, the mechanical tests will be combined simultaneously with other analytical, structure - and functional property-related test methods.

\subsection{Summary}

In this chapter a picture has been depicted of the ongoing research on interphase engineering with nanofillers in fiber-reinforced polymer composites. It turned out that the field represents a very exciting research area. In fact, several still open problems regarding interfaces and interphases in fibrous polymer composites could find a possible solution by exploiting some of the peculiar features of nanofillers. First of all, their dimensions in the nanometric range are fully compatible with the highly packed structure of composites containing elevated volume fractions of reinforcing fibers. In fact, nanofillers can be conveniently deposited on the surface of the reinforcements by different techniques resulting in physical or chemical adhesion. Moreover, practically all nanofillers can be properly functionalized to enhance their chemical compatibility with both fibers and matrices. On the other hand, bulk matrix modification can also be a valuable strategy to enhance the interphase properties. The possibility to modify both mechanical and functional properties of interphases by a proper selection of nanofillers and dispersion/localization of the same in the composite materials also stimulated the imagination of researchers. As a result, new composite materials with sensing/damage detection, self-healing/repair and damping capabilities have been successfully prepared by nanomodification of interphases.

\subsection{Acknowledgements}

The work reported here was partly supported by a grant from the Hungarian Research Funds (OTKA SNN 114547). This work was also supported by the European Union and the State of Hungary, co-financed by the European Social Fund, in the framework of TÁMOP-4.2.4.A/2-11/1-2012-0001 "National Excellence Program" (S. K.). 


\subsection{Nomenclature}

$\begin{array}{ll}\text { AF } & \text { aramid fiber } \\ \text { BF } & \text { basalt fiber } \\ \text { CF } & \text { carbon fiber } \\ \text { CNF } & \text { carbon nanofiber } \\ \text { CNT } & \text { carbon nanotube } \\ \text { CVD } & \text { chemical vapour deposition } \\ \text { DWCNT } & \text { double-walled carbon nanotube } \\ \text { EP } & \text { epoxy resin } \\ \text { EPD } & \text { electrophoretic deposition } \\ \text { ESD } & \text { electrostatic deposition } \\ \text { G } & \text { critical value of the strain energy release rate under mode I } \\ \text { GF } & \text { glass fiber } \\ \text { GNP } & \text { graphite nanoplatelet } \\ \text { GO } & \text { graphene oxide } \\ \text { GSD } & \text { graphitic structures by design } \\ \text { IFSS } & \text { interfacial shear strength } \\ \text { ILSS } & \text { interlaminar shear strength } \\ \text { LCP } & \text { liquid crystalline polymer } \\ \text { MWCNT } & \text { multi-walled carbon nanotube } \\ \text { NF } & \text { natural fiber } \\ \text { PAN } & \text { polyacrylonitrile } \\ \text { PBO } & \text { polybenzoxazole } \\ \text { PEI } & \text { polyethyleneimine } \\ \text { PET } & \text { poly(ethylene terephthalate) } \\ \text { PP } & \text { polypropylene } \\ \text { SBS } & \text { short beam shear } \\ \text { SWCNT } & \text { single-walled carbon nanotube } \\ \text { UD } & \text { unidirectional } \\ \text { UHMWPE } & \text { ultra-high molecular weight polyethylene } \\ \text { UP } & \text { unsatured polyester resin } \\ \text { VE } & \text { vinyl ester resin } \\ & \end{array}$

\section{References}

1. G. C. Papanicolaou, A. S. Paipetis and P. S. Theocaris, The concept of boundary interphase in composite mechanics, Colloid. Polym. Sci. 256, 625-630, 1978.

2. W. T. Y. Tze, D. J. Gardner, C. P. Tripp and S. C. O’Neill, Cellulose fiber/ polymer adhesion: Effects of fiber/matrix interfacial chemistry on the 
micromechanics of the interphase, J. Adhesion Sci. Technol. 20, 1649-1668, 2006.

3. F. R. Jones, Interfacial analysis in fiber composite materials, in Wiley Encyclopedia of Composites, L. Nicolais, A. Borzacchiello (Eds.), Second Edition, John Wiley \& Sons, Hoboken, NJ, USA, 2012.

4. M. Sharma, S. L. Gao, E. Mader, H. Sharma, L. Y. Wei and J. Bijwe, Carbon fiber surfaces and composite interphases, Composites Sci. Technol. 102, 35-50, 2014.

5. J. Karger-Kocsis, H. Mahmood and A. Pegoretti, Recent advances in fiber/ matrix interphase engineering for polymer composites, Prog. Mater Sci. 73, 1-43, 2015.

6. K. K. Chee Ho, H. Qian and A. Bismarck, Carbon fiber: Surface properties, in Wiley Encyclopedia of Composites, L. Nicolais, A. Borzacchiello (Eds.), Second Edition, John Wiley \& Sons, Hoboken, NJ, USA, 2012.

7. A. N. Netravali and K. L. Mittal, Fiber surface treatment: Relevance to interfacial characteristics, in Wiley Encyclopedia of Composites, L. Nicolais, A. Borzacchiello (Eds.), Second Edition, John Wiley \& Sons, Hoboken, NJ, USA, 2012.

8. M. A. Fuqua, S. S. Huo and C. A. Ulven, Natural fiber reinforced composites, Polym. Rev. 52, 259-320, 2012.

9. M. Pommet, J. Juntaro, J. Y. Heng, A. Mantalaris, A. F. Lee, K. Wilson, G. Kalinka, M. S. Shaffer and A. Bismarck, Surface modification of natural fibers using bacteria: Depositing bacterial cellulose onto natural fibers to create hierarchical fiber reinforced nanocomposites, Biomacromolecules 9, 1643-1651, 2008.

10. P. J. Herrera-Franco and L. T. Drzal, Comparison of methods for the measurement of fiber-matrix adhesion in composites, Composites 23, 2-27, 1992.

11. J.-K. Kim and Y.-M. Mai, Engineered Interfaces in Fiber Reinforced Composites, Elsevier, Amsterdam, 1998.

12. A. H. Barber, Q. Zhao, H. D. Wagner and C. A. Baillie, Characterization of E-glass-polypropylene interfaces using carbon nanotubes as strain sensors, Composites Sci. Technol. 64, 1915-1919, 2004.

13. S. L. Gao, R. C. Zhuang, J. Zhang, J. W. Liu and E. Mäder, Glass fibers with carbon nanotube networks as multifunctional sensors, Adv. Funct. Mater. 20, 1885-1893, 2010.

14. A. Warrier, A. Godara, O. Rochez, L. Mezzo, F. Luizi, L. Gorbatikh, S. V. Lomov, A. W. VanVuure and I. Verpoest, The effect of adding carbon nanotubes to glass/epoxy composites in the fibre sizing and/or the matrix, Composites Part A 41, 532-538, 2010.

15. J. E. Zhang, R. C. Zhuang, J. W. Liu, E. Mäder, G. Heinrich and S. L. Gao, Functional interphases with multi-walled carbon nanotubes in glass fibre/ epoxy composites, Carbon 48, 2273-2281, 2010.

16. L. Liao, X. Wang, P. Fang, K. M. Liew and C. Pan, Interface enhancement of glass fiber reinforced vinyl ester composites with flame-synthesized carbon 
nanotubes and its enhancing mechanism, ACS Appl. Mater. Interfaces 3, 534-538, 2011.

17. A. Battisti, D. Esque-de los Ojos, R. Ghisleni and A. J. Brunner, Single fiber push-out characterization of interfacial properties of hierarchical CNTcarbon fiber composites prepared by electrophoretic deposition, Composites Sci. Technol. 95, 121-127, 2014.

18. W. H. Liao, H. W. Tien, S. T. Hsiao, S. M. Li, Y. S. Wang, Y. L. Huang, S. Y. Yang, C. C. Ma and Y. F. Wu, Effects of multiwalled carbon nanotubes functionalization on the morphology and mechanical and thermal properties of carbon fiber/vinyl ester composites, ACS Appl. Mater. Interfaces 5, 3975-3982, 2013.

19. R. C. Zhuang, T. L. D. Thi, J. W. Liu, J. Zhang, S. L. Gao and E. Mäder, Multifunctional multi-walled carbon nanotube-jute fibres and composites, Carbon 49, 2683-2692, 2011.

20. Y. Li, C. Z. Chen, J. Xu, Z. S. Zhang, B. Y. Yuan and X. L. Huang, Improved mechanical properties of carbon nanotubes-coated flax fiber reinforced composites, J. Mater. Sci. 50, 1117-1128, 2015.

21. G. Lee, K. D. Ko, Y. C. Yu, J. Lee, W. R. Yu and J. H. Youk, A facile method for preparing CNT-grafted carbon fibers and improved tensile strength of their composites, Composites Part A 69, 132-138, 2015.

22. G. Tang, Z. L. Zang, D. F. Chang, G. F. Wei, D. M. Wang, W. J. Mi, W. Yan and W. J. Huang, Study on the interfacial behavior of clay-coated carbon fiberreinforced PEI composites, Polym.-Plast. Technol. 51, 861-865, 2012.

23. L. Chen, H. Jin, Z. W. Xu, M. J. Shan, X. Tian, C. Y. Yang, Z. Wang and B. W. Cheng, A design of gradient interphase reinforced by silanized graphene oxide and its effect on carbon fiber/epoxy interface, Mater. Chem. Phys. 145, 186-196, 2014.

24. W. Qin, F. Vautard, L. T. Drzal and J. Yu, Mechanical and electrical properties of carbon fiber composites with incorporation of graphene nanoplatelets at the fiber-matrix interphase, Composites Part B 69, 335-341, 2015.

25. L. Chen, H. Jin, Z. W. Xu, J. L. Li, Q. W. Guo, M. J. Shan, C. Y. Yang, Z. Wang, W. Mai and B. W. Cheng, Role of a gradient interface layer in interfacial enhancement of carbon fiber/epoxy hierarchical composites, J. Mater. Sci. 50, 112-121, 2015.

26. F. Gauvin, P. Cousin and M. Robert, Improvement of the interphase between basalt fibers and vinylester by nano-reinforced post-sizing, Fibers Polym. 16, 434-442, 2015.

27. T. Kamae and L. T. Drzal, Carbon fiber/epoxy composite property enhancement through incorporation of carbon nanotubes at the fiber-matrix interphase - Part I: The development of carbon nanotube coated carbon fibers and the evaluation of their adhesion, Composites Part A 43, 1569-1577, 2012.

28. B. H. Rutz and J. C. Berg, Electrostatic deposition of silica nanoparticles between E-glass fibers and an epoxy resin, J. Appl. Polym. Sci. 132, 41487, 2015 . 
29. A. J. Rodriguez, M. E. Guzman, C. S. Lim and B. Minaie, Synthesis of multiscale reinforcement fabric by electrophoretic deposition of amine-functionalized carbon nanofibers onto carbon fiber layers, Carbon 48, 3256-3259, 2010.

30. J. Zhang, J. Liu, R. Zhuang, E. Mäder, G. Heinrich and S. Gao, Single MWNTglass fiber as strain sensor and switch, Adv. Mater. 23, 3392-3397, 2011.

31. A. J. Rodriguez, M. E. Guzman, C. S. Lim and B. Minaie, Mechanical properties of carbon nanofiber/fiber-reinforced hierarchical polymer composites manufactured with multiscale-reinforcement fabrics, Carbon 49, 937-948, 2011.

32. G. H. Zhou, J. H. Byun, Y. Q. Wang, H. J. Cha, J. U. Lee, B. M. Jung, J. I. Song, B. S. Kim and T. W. Chou, Mechanism of sonication-assisted electrophoretic deposition of carbon nano-fiber on carbon fabrics, Composites Sci. Technol. 107, 29-35, 2015.

33. G. Zhang, Z. Rasheva, J. Karger-Kocsis and T. Burkhart, Synergetic role of nanoparticles and micro-scale short carbon fibers on the mechanical profiles of epoxy resin, Express Polym. Lett. 5, 859-872, 2011.

34. S. V. Lomov, L. Gorbatikh, Z. Kotanjac, V. Koissin, M. Houlle, O. Rochez, M. Karahan, L. Mezzo and I. Verpoest, Compressibility of carbon woven fabrics with carbon nanotubes/nanofibres grown on the fibres, Composites Sci. Technol. 71, 315-325, 2011.

35. A. Bianco, H. M. Cheng, T. Enoki, Y. Gogotsi, R. H. Hurt, N. Koratkar, T. Kyotani, M. Monthioux, C. R. Park, J. M. D. Tascon and J. Zhang, All in the graphene family - A recommended nomenclature for two-dimensional carbon materials, Carbon 65, 1-6, 2013.

36. J. Chen, D. Zhao, X. Jin, C. Wang, D. Wang and H. Ge, Modifying glass fibers with graphene oxide: Towards high-performance polymer composites, Composites Sci. Technol. 97, 41-45, 2014.

37. J. Rabotnov, B. Perov, V. Lutsan, T. Ssorina and E. Stepanitsov, Carbon fibers. Their place in modern technology, in Proc. 2nd Carbon Fibre Conf., The Plastics Institute, London, p. 65, 1974.

38. W. B. Downs and R. T. K. Baker, Novel carbon fiber-carbon filament structures, Carbon 29, 1173-1179, 1991.

39. E. T. Thostenson, W. Z. Li, D. Z. Wang, Z. F. Ren and T. W. Chou, Carbon nanotube/carbon fiber hybrid multiscale composites, J. Appl. Phys. 91, 6034-6037, 2002.

40. H. Qian, E. S. Greenhalgh, M. S. P. Shaffer and A. Bismarck, Carbon nanotube-based hierarchical composites: A review, J. Mater. Chem. 20, 4751, 2010.

41. C. D. Wood, M. J. Palmeri, K. W. Putz, G. Ho, R. Barto and L. C. Brinson, Nanoscale structure and local mechanical properties of fiber-reinforced composites containing MWCNT-grafted hybrid glass fibers, Composites Sci. Technol. 72, 1705-1710, 2012.

42. A. Rahaman and K. K. Kar, Carbon nanomaterials grown on E-glass fibers and their application in composite, Composites Sci. Technol. 101, 1-10, 2014. 
43. R. J. Sager, P. J. Klein, D. C. Lagoudas, Q. Zhang, J. Liu, L. Dai and J. W. Baur, Effect of carbon nanotubes on the interfacial shear strength of T650 carbon fiber in an epoxy matrix, Composites Sci. Technol. 69, 898-904, 2009.

44. S. P. Sharma and S. C. Lakkad, Effect of CNTs growth on carbon fibers on the tensile strength of CNTs grown carbon fiber-reinforced polymer matrix composites, Composites Part A 42, 8-15, 2011.

45. P. Lv, Y. Y. Feng, P. Zhang, H. M. Chen, N. Q. Zhao and W. Feng, Increasing the interfacial strength in carbon fiber/epoxy composites by controlling the orientation and length of carbon nanotubes grown on the fibers, Carbon 49, 4665-4673, 2011.

46. O. Boura, E. K. Diamanti, S. A. Grammatikos, D. Gournis and A. S. Paipetis, Carbon nanotube growth on high modulus carbon fibres: Morphological and interfacial characterization, Surf. Interface Anal. 45, 1372-1381, 2013.

47. F. An, C. X. Lu, Y. H. Li, J. H. Guo, X. X. Lu, H. B. Lu, S. Q. He and Y. Yang, Preparation and characterization of carbon nanotube-hybridized carbon fiber to reinforce epoxy composite, Mater. Design 33, 197-202, 2012.

48. N. De Greef, L. Zhang, A. Magrez, L. Forró, J.-P. Locquet, I. Verpoest and J. W. Seo, Direct growth of carbon nanotubes on carbon fibers: Effect of the CVD parameters on the degradation of mechanical properties of carbon fibers, Diamond Relat. Mater. 51, 39-48, 2015.

49. H. Kim, E. Oh, H. T. Hahn and K. H. Lee, Enhancement of fracture toughness of hierarchical carbon fiber composites via improved adhesion between carbon nanotubes and carbon fibers, Composites Part A 71, 72-83, 2015.

50. P. Agnihotri, S. Basu and K. K. Kar, Effect of carbon nanotube length and density on the properties of carbon nanotube-coated carbon fiber/polyester composites, Carbon 49, 3098-3106, 2011.

51. E. J. Garcia, B. L. Wardle, A. J. Hart and N. Yamamoto, Fabrication and multifunctional properties of a hybrid laminate with aligned carbon nanotubes grown in situ, Composites Sci. Technol. 68, 2034-2041, 2008.

52. Q. Zhang, W. Z. Qian, R. Xiang, Z. Yang, G. H. Luo, Y. Wang and F. Wei, In situ growth of carbon nanotubes on inorganic fibers with different surface properties, Mater. Chem. Phys. 107, 317-321, 2008.

53. L. Jin, L. Zhang, D. H. Su and C. Z. Li, Direct growth of aligned carbon nanotubes on quartz fibers for structural epoxy composites, Ind. Eng. Chem. Res. 51, 4927-4933, 2012.

54. V. P. Veedu, A. Y. Cao, X. S. Li, K. G. Ma, C. Soldano, S. Kar, P. M. Ajayan and M. N. Ghasemi-Nejhad, Multifunctional composites using reinforced laminae with carbon-nanotube forests, Nature Materials 5, 457-462, 2006.

55. H. Qian, A. Bismarck, E. S. Greenhalgh and M. S. P. Shaffer, Carbon nanotube grafted silica fibres: Characterising the interface at the single fibre level, Composites Sci. Technol. 70, 393-399, 2010.

56. G. J. Ehlert and H. A. Sodano, Zinc oxide nanowire interphase for enhanced interfacial strength in lightweight polymer fiber composites, ACS Appl. Mater. Interfaces 1, 1827-1833, 2009. 
57. G. J. Ehlert, U. Galan and H. A. Sodano, Role of surface chemistry in adhesion between $\mathrm{ZnO}$ nanowires and carbon fibers in hybrid composites, ACS Appl. Mater. Interfaces 5, 635-645, 2013.

58. B. K. Deka, K. Kong, J. Seo, D. Kim, Y. B. Park and H. W. Park, Controlled growth of $\mathrm{CuO}$ nanowires on woven carbon fibers and effects on the mechanical properties of woven carbon fiber/polyester composites, Composites Part A 69, 56-63, 2015.

59. Y. R. Lin, G. Ehlert and H. A. Sodano, Increased interface strength in carbon fiber composites through a $\mathrm{ZnO}$ nanowire interphase, Adv. Funct. Mater. 19, 2654-2660, 2009.

60. Y. X. Zhang, X. L. Guo, M. Huang, X. D. Hao, Y. Yuan and C. Hua, Engineering birnessite-type $\mathrm{MnO} 2$ nanosheets on fiberglass for $\mathrm{pH}$-dependent degradation of methylene blue, J. Phys. Chem. Solids 83, 40-46, 2015.

61. F. Paladini, R. A. Picca, M. C. Sportelli, N. Cioffi, A. Sannino and M. Pollini, Surface chemical and biological characterization of flax fabrics modified with silver nanoparticles for biomedical applications, Mater. Sci. Eng., C 52, 1-10, 2015.

62. L. T. Drzal, The interphase in epoxy composites, Adv. Polym. Sci. 75, 1-32, 1986.

63. J. Zhang, S. Deng, Y. Wang, L. Ye, L. Zhou and Z. Zhang, Effect of nanoparticles on interfacial properties of carbon fibre-epoxy composites, Composites Part A 55, 35-44, 2013.

64. M. K. Hossain, M. M. R. Chowdhury, M. B. Salam, J. Malone, M. V. Hosur, $\mathrm{S}$. Jeelani and N. W. Bolden, Improved thermomechanical properties of carbon fiber reinforced epoxy composite using amino functionalized XDCNT, $J$. Appl. Polym. Sci. 131, 40709, 2014.

65. L. Ma, L. Wu, X. Cheng, D. Zhuo, Z. Weng and R. Wang, Improving the interlaminar properties of polymer composites using a situ accumulation method to construct the multi-scale reinforcement of carbon nanofibers/carbon fibers, Composites Part A 72, 65-74, 2015.

66. F. H. Gojny, M. H. G. Wichmann, B. Fiedler, W. Bauhofer and K. Schulte, Influence of nano-modification on the mechanical and electrical properties of conventional fibre-reinforced composites, Composites Part A 36, 1525-1535, 2005.

67. R. Sadeghian, S. Gangireddy, B. Minaie and K.-T. Hsiao, Manufacturing carbon nanofibers toughened polyester/glass fiber composites using vacuum assisted resin transfer molding for enhancing the mode-I delamination resistance, Composites Part A 37, 1787-1795, 2006.

68. A. Dorigato, S. Morandi and A. Pegoretti, Effect of nanoclay addition on the fiber/matrix adhesion in epoxy/glass composites, J. Composite Mater. 46, 1439-1451, 2012.

69. D. Pedrazzoli, A. Pegoretti and K. Kalaitzidou, Synergistic effect of exfoliated graphite nanoplatelets and short glass fiber on the mechanical and interfacial properties of epoxy composites, Composites Sci. Technol. 98, 15-21, 2014. 
70. D. Pedrazzoli and A. Pegoretti, Silica nanoparticles as coupling agents for polypropylene/glass composites, Composites Sci. Technol. 76, 77-83, 2013.

71. D. Pedrazzoli and A. Pegoretti, Expanded graphite nanoplatelets as coupling agents in glass fiber reinforced polypropylene composites, Composites Part A 66, 25-34, 2014.

72. Y. Arao, S. Yumitori, H. Suzuki, T. Tanaka, K. Tanaka and T. Katayama, Mechanical properties of injection-molded carbon fiber/polypropylene composites hybridized with nanofillers, Composites Part A 55, 19-26, 2013.

73. D. P. N. Vlasveld, P. P. Parlevliet, H. E. N. Bersee and S. J. Picken, Fibre-matrix adhesion in glass-fibre reinforced polyamide- 6 silicate nanocomposites, Composites Part A 36, 1-11, 2005.

74. W. Daud, H. E. N. Bersee, S. J. Picken and A. Beukers, Layered silicates nanocomposite matrix for improved fiber reinforced composites properties, Composites Sci. Technol. 69, 2285-2292, 2009.

75. N. A. Isitman, M. Aykol and C. Kaynak, Nanoclay assisted strengthening of the fiber/matrix interface in functionally filled polyamide 6 composites, Composite Struct. 92, 2181-2186, 2010.

76. B. Fiedler, F. Gojny, M. Wichmann, W. Bauhofer and K. Schulte, Can carbon nanotubes be used to sense damage in composites?, Eur. J. Control 29, 81-94, 2004.

77. T.-W. Chou, L. Gao, E. T. Thostenson, Z. Zhang and J.-H. Byun, An assessment of the science and technology of carbon nanotube-based fibers and composites, Composites Sci. Technol. 70, 1-19, 2010.

78. S. Luo, W. Obitayo and T. Liu, SWCNT-thin-film-enabled fiber sensors for lifelong structural health monitoring of polymeric composites - From manufacturing to utilization to failure, Carbon 76, 321-329, 2014.

79. H. Zhang, Y. Liu, M. Kuwata, E. Bilotti and T. Peijs, Improved fracture toughness and integrated damage sensing capability by spray coated CNTs on carbon fibre prepreg, Composites Part A 70, 102-110, 2015.

80. Y. Lin and H. A. Sodano, Concept and model of a piezoelectric structural fiber for multifunctional composites, Composites Sci. Technol. 68, 1911-1918, 2008.

81. B. J. Blaiszik, S. L. B. Kramer, S. C. Olugebefola, J. S. Moore, N. R. Sottos and S. R. White, Self-healing polymers and composites, Annu Rev Mater Res 40, 179-211, 2010.

82. A. R. Jones, B. J. Blaiszik, S. R. White and N. R. Sottos, Full recovery of fiber/ matrix interfacial bond strength using a microencapsulated solvent-based healing system, Composites Sci. Technol. 79, 1-7, 2013.

83. A. R. Jones, A. Cintora, S. R. White and N. R. Sottos, Autonomic healing of carbon fiber/epoxy interfaces, ACS Appl. Mater. Interfaces 6, 6033-6039, 2014.

84. R. Chandra, S. P. Singh and K. Gupta, A study of damping in fiber-reinforced composites, J. Sound Vibration 262, 475-496, 2003.

85. M. Tehrani, M. Safdari, A. Y. Boroujeni, Z. Razavi, S. W. Case, K. Dahmen, H. Garmestani and M. S. Al-Haik, Hybrid carbon fiber/carbon nanotube composites for structural damping applications, Nanotechnology 24, 155704, 2013. 
86. D. A. Jesson and J. F. Watts, The interface and interphase in polymer matrix composites: Effect on mechanical properties and methods for identification, Polym. Rev. 52, 321-354, 2012.

87. A. Kafi, M. Huson, C. Creighton, J. Khoo, L. Mazzola, T. Gengenbach, F. Jones and B. Fox, Effect of surface functionality of PAN-based carbon fibres on the mechanical performance of carbon/epoxy composites, Composites Sci. Technol. 94, 89-95, 2014.

88. S. Y. Jin, R. J. Young and S. J. Eichhorn, Controlling and mapping interfacial stress transfer in fragmented hybrid carbon fibre-carbon nanotube composites, Composites Sci. Technol. 100, 121-127, 2014.

89. A. M. Díez-Pascual, M. A. Gómez-Fatou, F. Ania and A. Flores, Nanoindentation assessment of the interphase in carbon nanotube-based hierarchical composites, J. Phys. Chem. C 116, 24193-24200, 2012.

90. Y. X. Li, M. Li, Y. Z. Gu, Z. G. Zhang and P. Q. Guan, Investigation of the nanoscale mechanical properties of carbon fiber/epoxy resin interphase. I. Analysis of fiber-stiffening effect during the nanoindentation process based on numerical simulation, Polym. Composites 33, 1387-1394, 2012.

91. H. Qian, G. Kalinka, K. L. Chan, S. G. Kazarian, E. S. Greenhalgh, A. Bismarck and M. S. Shaffer, Mapping local microstructure and mechanical performance around carbon nanotube grafted silica fibres: Methodologies for hierarchical composites, Nanoscale 3, 4759-4767, 2011.

92. H. Qian, A. Bismarck, E. S. Greenhalgh, G. Kalinka and M. S. P. Shaffer, Hierarchical composites reinforced with carbon nanotube grafted fibers: The potential assessed at the single fiber level, Chem. Mater. 20, 1862-1869, 2008.

93. L. Yang, X. D. He, L. Mei, L. Y. Tong, R. G. Wang and Y. B. Li, Interfacial shear behavior of $3 \mathrm{D}$ composites reinforced with CNT-grafted carbon fibers, Composites Part A 43, 1410-1418, 2012.

94. V. S. Romanov, S. V. Lomov, I. Verpoest and L. Gorbatikh, Can carbon nanotubes grown on fibers fundamentally change stress distribution in a composite?, Composites Part A 63, 32-34, 2014.

95. L. Mishnaevsky, Nanostructured interfaces for enhancing mechanical properties of composites: Computational micromechanical studies, Composites Part B 68, 75-84, 2015.

96. X. Q. Wang, W. T. Zhao, B. Fang, S. W. Lu and Y. W. Zhang, Micromechanical analysis of long fiber-reinforced composites with nanoparticle incorporation into the interphase region, J. Appl. Polym. Sci. 132, 41592, 2015. 
